\title{
Imaging Findings Associated with Space-Occupying Edema in Patients with Large Middle Cerebral Artery Infarcts
}

\author{
(D) A.D. Horsch, (D).W. Dankbaar, (D)T.A. Stemerdink, (DE. Bennink, (D)T. van Seeters, (D).J. Kappelle, (D). Hofmeijer, (D) H.W. de Jong,
}

(D) Y. van der Graaf, and DB.K. Velthuis; on behalf of the DUST investigators

\begin{abstract}
BACKGROUND AND PURPOSE: Prominent space-occupying cerebral edema is a devastating complication occurring in some but not all patients with large MCA infarcts. It is unclear why differences in the extent of edema exist. Better knowledge of factors related to prominent edema formation could aid treatment strategies. This study aimed to identify variables associated with the development of prominent edema in patients with large MCA infarcts.
\end{abstract}

MATERIALS AND METHODS: From the Dutch Acute Stroke Study (DUST), 137 patients were selected with large MCA infarcts on follow-up NCCT ( $3 \pm 2$ days after stroke onset), defined as ASPECTS $\leq 4$. Prominent edema was defined as a midline shift of $\geq 5 \mathrm{~mm}$ on follow-up. Admission patient and treatment characteristics were collected. Admission CT parameters used were ASPECTS on NCCT and CBV and MTT maps, and occlusion site, clot burden, and collaterals on CTA. Permeability on admission CTP, and day 3 recanalization and reperfusion statuses were obtained if available. Unadjusted and adjusted (age and NIHSS) odds ratios were calculated for all variables in relation to prominent edema.

RESULTS: Prominent edema developed in 51 patients (37\%). Adjusted odds ratios for prominent edema were higher with lower ASPECTS on NCCT (adjusted odds ratio, 1.32; 95\% Cl, 1.13-1.55) and CBV (adjusted odds ratio, 1.26; 95\% Cl, 1.07-1.49), higher permeability (adjusted odds ratio, 2.35; 95\% Cl, 1.30-4.24), more proximal thrombus location (adjusted odds ratio, 3.40; 95\% Cl, 1.57-7.37), higher clot burden (adjusted odds ratio, 2.88; 95\% Cl, 1.11-7.45), and poor collaterals (adjusted odds ratio, 3.93; 95\% Cl, 1.78-8.69).

CONCLUSIONS: Extensive proximal occlusion, poor collaterals, and larger ischemic deficits with higher permeability play a role in the development of prominent edema in large MCA infarcts.

ABBREVIATIONS: $\mathrm{ACA}=$ anterior cerebral artery; ECASS = European Cooperative Acute Stroke Study

$\mathbf{P}$ rominent space-occupying edema can occur after acute large MCA ischemic stroke. The prominent space-occupying edema can cause herniation, increased intracranial pressure, and rapid neurologic deterioration. These occur in approximately $8 \%$ of MCA infarcts and have mortality rates of up to $80 \%$ with conservative treatment. ${ }^{1-3}$ Current treatment options are limited; the only treatment of proved value is large hemicraniectomy within

Received July 8, 2015; accepted after revision October 30.

From the Departments of Radiology (A.D.H., J.W.D., T.A.S., E.B., T.v.S., H.W.d.J. B.K.V.) and Neurology (L.J.K.), Utrecht Stroke Center, University Medical Center Utrecht, Utrecht, the Netherlands; Department of Neurology (J.H.), Rijnstate Hospital, Arnhem, the Netherlands; and Julius Center for Health Sciences and Primary Care (Y.v.d.G.), Utrecht, the Netherlands.

This study was supported by grants from the Netherlands Heart Foundation (grant numbers 2008 T034 and 2012 T061) and the NutsOhra Foundation (grant number 0903-012).

Please address correspondence to Alexander D. Horsch, MD, MRCS, University Medical Center Utrecht, Heidelberglaan 100, HP E01.132, 3584 CX Utrecht, the Netherlands; e-mail: alexanderhorsch@gmail.com

http://dx.doi.org/10.3174/ajnr.A4637
48 hours after stroke onset. ${ }^{4-6}$ The results from the hemicraniectomy trials showed a large decrease in mortality but with an increase in number of patients with severe disability. ${ }^{4}$

Although risk factors for prominent space-occupying edema have been identified, it is still unclear why only some patients with a large MCA infarct on follow-up develop prominent space-occupying edema. ${ }^{7}$ Identification of associated variables is important to identify possible new targets for treatment development. ${ }^{8}$

The extent of the disturbance of the blood-brain barrier may play a role in the development of prominent space-occupying edema. ${ }^{9}$ A measure of the $\mathrm{BBB}$ permeability is the permeability surface-area product, which can be obtained from an extended CTP acquisition. ${ }^{10}$ Other known risk factors for the development of prominent space-occupying edema include proximal occlusion site, greater infarct size, involvement of $>1$ vascular territory, basal ganglia involvement, increased ratio of CBV lesion volume/CSF volume, female sex, and higher NIHSS score on admission..$^{9,11-14}$ 
The aim of this study was to identify clinical and CT imaging variables that are associated with the development of prominent space-occupying edema in patients with large MCA infarcts on follow-up.

\section{MATERIALS AND METHODS \\ Patient Selection}

All patients participated in the Dutch Acute Stroke Study (DUST), and the study protocol has been published previously. ${ }^{15}$ Patients were included in the DUST study if they had a NCCT, CTA, and CTP within 9 hours after stroke onset. The local medical ethics committees of the participating centers approved this study. All patients or their families gave signed informed consent unless a patient died before consent could be obtained; in that case, the need for consent was waived by the medical ethics committee. ${ }^{15}$

For the current study, patients were selected with a large infarct in the MCA territory defined as ASPECTS $\leq 4$ on a follow-up NCCT performed $3 \pm 2$ days after stroke onset. ${ }^{16}$ Exclusion criteria were hemorrhagic transformation with substantial mass effect (European Cooperative Acute Stroke Study [ECASS] parenchymal hemorrhage type 2) and poor-quality admission CTP. ${ }^{17}$ The selection process is clarified in the flow chart (Fig 1). We collected clinical data on age, sex, history of stroke or atrial fibrillation, admission NIHSS, IV-rtPA treatment, intra-arterial treatment, and time from symptom onset to admission CT.

\section{Imaging Protocol}

NCCT and CTP of the brain and CTA of the cervical and cerebral arteries were performed on admission. Follow-up NCCT was planned at $3 \pm 2$ days and in case of clinical deterioration. Additional follow-up CTA and CTP were also performed if possible. Multidetector row CT scanners were used, with the number of detectors ranging from 40 to 320 (LightSpeed VCT, GE Healthcare, Milwaukee, Wisconsin; Brilliance 40, Brilliance 64, and Brilliance iCT 256, Philips Healthcare, Best, the Netherlands; Sensation 64, Siemens, Erlangen, Germany; Aquilion ONE, Toshiba Medical Systems, Tokyo, Japan). NCCT was performed with $120 \mathrm{kV}, 300-375 \mathrm{mAs}$, and a section thickness of $5 \mathrm{~mm}$.

The CTP, performed before CTA, was acquired with $80 \mathrm{kV}$ and $150 \mathrm{mAs}$ per rotation and a section thickness of $5 \mathrm{~mm}$ and involved successive gantry rotations in cine mode (every 2 seconds for 50 seconds and 6 additional rotations 30 seconds apart) during intravenous administration of $40 \mathrm{~mL}$ of nonionic contrast material followed by $40 \mathrm{~mL}$ of saline with a flow of $6 \mathrm{~mL} / \mathrm{s}$. CTP coverage included at least the level of the basal ganglia to the lateral ventricles to allow assessment of both ASPECTS levels. ${ }^{16}$ MTT and CBV maps were classified only with ASPECTS levels to ensure that uniform assessment on all CTP scans was performed, despite differences in scan range (40-320 sections).

CTA was acquired from the aortic arch to the vertex with $50-70 \mathrm{~mL}$ of contrast followed by $40 \mathrm{~mL}$ of saline, with a flow of $6 \mathrm{~mL} / \mathrm{s}$. The individual CTA scan delay after intravenous injection was calculated from time-to-peak arterial enhancement on CTP

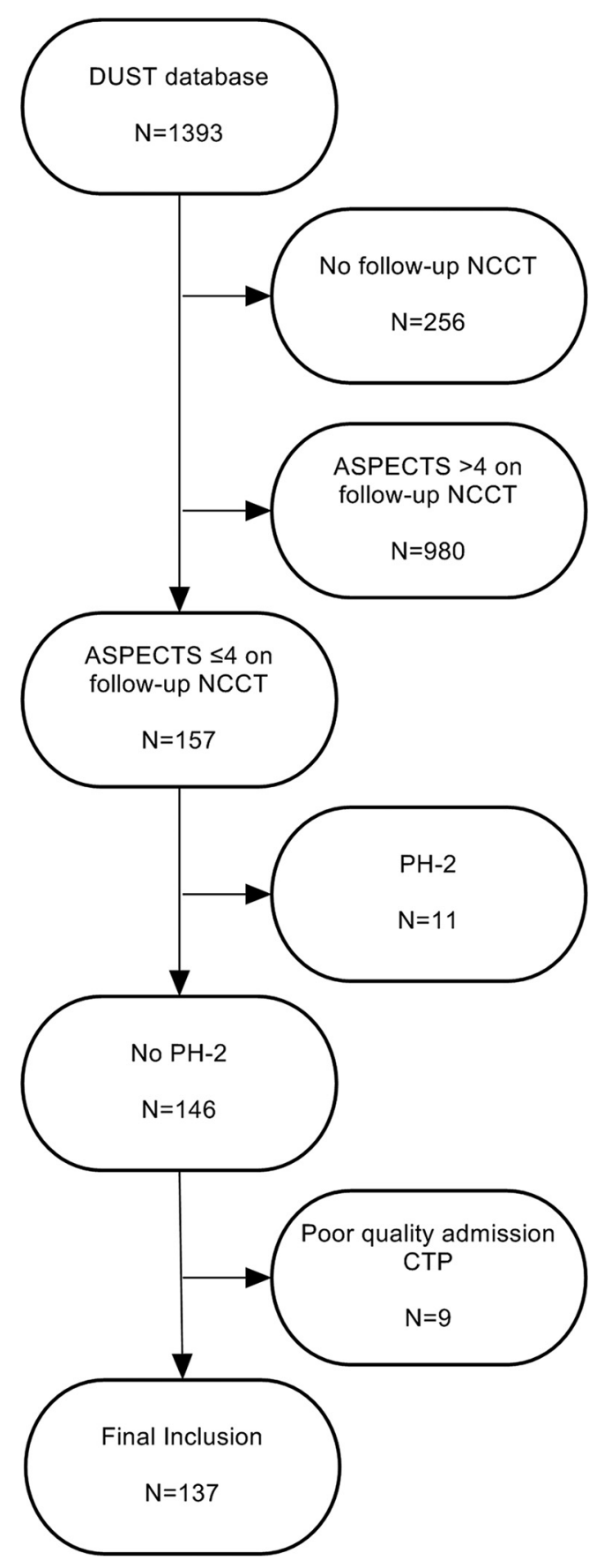

FIG 1. Inclusion flow chart. PH indicates parenchymal hemorrhage.

or by a trigger-based Hounsfield unit threshold measurement of contrast enhancement in the aortic arch.

\section{Imaging Analysis}

NCCT. On the admission scan, we evaluated the ASPECTS score to quantify the presence of early CT signs of infarction. ${ }^{16}$ On day $3 \pm 2$ of follow-up, the infarct size was classified with ASPECTS and the presence of prominent space-occupying edema was defined as a midline shift of $\geq 5 \mathrm{~mm}$ (Fig 2). ${ }^{11,18,19}$ Any hemorrhagic transformation on the follow-up scan was classified according to the ECASS criteria to identify patients with a parenchymal hemorrhage type 2 (hemorrhage of $>30 \%$ of the infarcted area with 


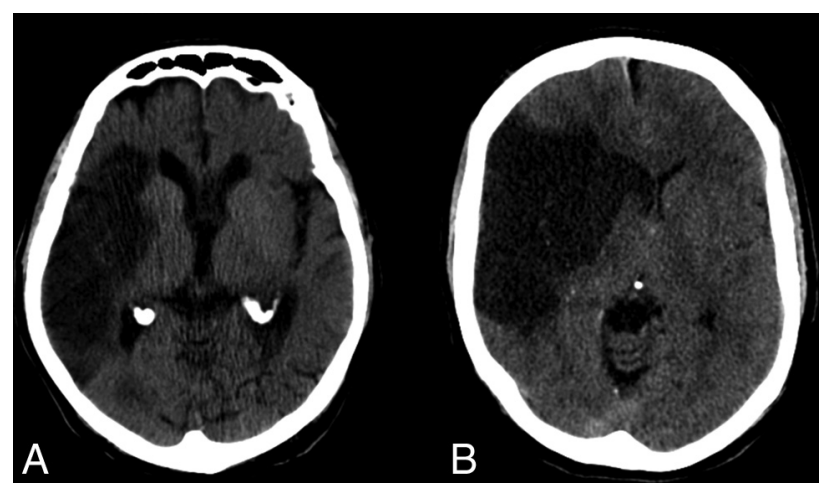

FIG 2. Large MCA infarct on follow-up, with and without prominent space-occupying edema. Patient A (87-year-old man, follow-up day 5) has a large MCA infarct and generalized atrophy but does not show a midline shift. Patient B (58-year-old man, follow-up day 3) has a large MCA infarct with a midline shift of $\geq 5 \mathrm{~mm}$, representing prominent space-occupying edema.

substantial space-occupying effect), because the midline shift in those patients is considered secondary to the large hemorrhage. ${ }^{17}$

CTP. CBF, CBV, MTT, and TTP were automatically calculated from CTP data using commercially available CTP software (Extended Brilliance Workstation 4.5; Philips Healthcare). The presence of a perfusion deficit on admission was defined as a focal asymmetry on the CBF, CBV, or MTT maps matching a part of or the complete MCA flow territory. MTT and CBV maps were classified with ASPECTS. ${ }^{20}$ Involvement of the lentiform nucleus and additional anterior cerebral artery (ACA) vascular territory (including the caudate nucleus) was also evaluated separately. ${ }^{1,21}$ Reperfusion was evaluated quantitatively by assessment of the change in MTT abnormality (Soares et $\mathrm{al}^{22}$ ) and categorized into reperfusion and no-reperfusion groups. Reperfusion was defined as a resolution of $\geq 75 \%$ of the abnormality on the MTT maps comparing admission and follow-up CTP. ${ }^{22}$

To estimate the permeability surface area, we used a nonlinear method, with a mathematic response model to describe an impulse response function obtained from the extended acquisition. The permeability surface area was calculated relative to the nonaffected hemisphere. ${ }^{10}$

CTA. Admission CTA provided data on intracranial thrombus location, clot burden score, and collateral score. ${ }^{23-25}$ Thrombus location was classified as the most proximal site of occlusion, unless there was a combined extracranial ICA occlusion and a more distal MCA occlusion with an open ICA top (tandem lesion), which was classified at the level of the MCA occlusion (proximal flow maintained through circle of Willis collaterals). ${ }^{26}$ The clot burden score was obtained by evaluating the anterior circulation to the symptomatic hemisphere and subtracting segments with absent contrast opacification from the maximum score of 10, with 10 representing absence of any thrombus, and zero, a complete occlusion of all the segments. The score assigns 1 point to the infraclinoid ICA, the ACA, and each M2 branch (with a maximum of 2) and 2 points to the supraclinoid part of the ICA and the proximal and distal part of the M1 segment. ${ }^{23}$

The collateral score of the symptomatic hemisphere was evaluated by visual assessment of MIP images and the scoring system applied by Tan et al. ${ }^{24}$ Leptomeningeal collaterals were graded on admission CTA by the extent of collateral filling in the MCA territory of the affected hemisphere in comparison with the contralateral side: $0=$ absent; $1=$ filling $\leq 50 \% ; 2=$ filling $50 \%$ to $<100 \% ; 3=$ filling $100 \%$. For analysis, the scores were dichotomized into poor collaterals $(0-1)$ and good collaterals (2-3). Tan et al found a very good interobserver correlation of 0.87 for this scoring system. Recanalization was evaluated by comparing admission and follow-up CTAs and was defined qualitatively as recanalization or no recanalization. This scoring system compares with a TICI score of $0-2 \mathrm{a}$ for the no-recanalization group and a TICI score of $2 \mathrm{~b}$ or 3 for the recanalization group. ${ }^{27}$

All imaging data were collected and evaluated centrally by 1 of 3 observers (I.C. van der Schaaf, B.K.V., and J.W.D), all with at least 5 years of experience in stroke imaging. Only the symptomatic side was provided for the evaluation.

\section{Statistical Analysis}

For all analyses, patients with prominent space-occupying edema were compared with patients without prominent space-occupying edema. The clinical variables were age, sex, history of stroke, history of atrial fibrillation, admission NIHSS, IV-rtPA treatment or intra-arterial treatment, and time to admission scan series. Imaging variables were the following: early CT signs of infarction (ASPECTS 0-10), decreased CBV (ASPECTS 0-10), prolonged MTT (ASPECTS 0-10), the presence of decreased CBV in the lentiform nucleus (yes/no), the presence of decreased CBV in the caudate nucleus and/or ACA vascular territory (yes/no), clot burden score (cutoff of $\leq 6$ ), thrombus location (ICA/proximal M1 versus distal M1, M2, or $>$ M2), and collateral score (good or poor). ${ }^{24}$ Permeability estimates, recanalization (recanalization versus no recanalization), and reperfusion (reperfusion versus no reperfusion) were analyzed in a subanalysis because these data were not available in all patients.

To compare variables, we used the $\chi^{2}$ test, $t$ test, or MannWhitney $U$ test. The association between variables and prominent space-occupying edema was analyzed by using univariate and multivariate regression. Odds ratios were adjusted for age and admission NIHSS score (adjusted OR) with multivariate logistic regression. Significance was predefined at $P<.05$. Statistical computations were performed by using SPSS 23.0 (IBM, Armonk, New York).

\section{RESULTS}

Inclusion criteria for this study were met in 137 patients. Not all patients in the DUST study underwent follow-up imaging, for the following reasons: no permission for follow-up, no follow-up due to discharge within 24 hours in patients with rapid recovery, poor condition of the patient, or impaired renal function. Admission NIHSS and 3-month mRS scores were not significantly different between patients with or without follow-up imaging.

Of the 137 patients with large MCA infarcts on follow-up, 51 (37\%) developed prominent space-occupying edema. Their baseline clinical and imaging characteristics are shown in Table 1. Median onset time to imaging was 100 minutes, and most patients (88\%) were imaged within 4.5 hours. Only 6\% were imaged within the 6- to 9-hour range. The median time to follow-up was 


\begin{tabular}{|c|c|c|c|c|}
\hline Characteristics & $\begin{array}{l}\text { All Patients } \\
(N=137)\end{array}$ & $\begin{array}{c}\text { Prominent } \\
\text { Space-Occupying } \\
\text { Edema }(n=51)\end{array}$ & $\begin{array}{l}\text { No Prominent } \\
\text { Space-Occupying } \\
\text { Edema }(n=86)\end{array}$ & $P$ Value \\
\hline \multicolumn{5}{|l|}{ Clinical parameters } \\
\hline Age (yr) (median) (IQR) & $66(53-73)$ & $63(52-72)$ & $67(54-73)$ & .31 \\
\hline Female sex (No.) (\%) & $48(35)$ & $19(37)$ & $29(34)$ & .68 \\
\hline Prior stroke (No.) (\%) & $20(15)^{\prime}$ & $10(20)$ & $10(12)$ & .18 \\
\hline Atrial fibrillation (No.) (\%) & $16(12)$ & $8(16)$ & $8(9)$ & .27 \\
\hline NIHSS (median) (IQR) & $15(12-19)$ & $18(13-21)$ & $14(11-18)$ & $.01^{\mathrm{b}}$ \\
\hline IV-rtPA (No.) (\%) & $94(69)$ & $32(63)$ & $62(72)$ & .25 \\
\hline Intra-arterial treatment (No.) (\%) & $29(21)$ & $11(22)$ & $18(21)$ & .93 \\
\hline \multicolumn{5}{|l|}{ Imaging parameters } \\
\hline Time to admission scan (min) (median) (IQR) & $100(64-152)$ & $106(70-240)$ & $91(63-135)$ & .11 \\
\hline \multicolumn{5}{|l|}{ NCCT } \\
\hline Early CT signs of infarction, ASPECTS, (median) (IQR) & $8(6-10)$ & $7(4-9)$ & $9(7-10)$ & $.0001^{\mathrm{b}}$ \\
\hline \multicolumn{5}{|l|}{ CTP } \\
\hline CBV deficit, ASPECTS (mean) (SD) & $4.30(2.57)$ & $3.31(2.32)$ & $4.89(2.54)$ & $.001^{\mathrm{b}}$ \\
\hline MTT deficit, ASPECTS (median) (IQR) & $1(0-3)$ & $1(0-3)$ & $2(0-3)$ & .11 \\
\hline CBV deficit in lentiform nucleus (No.) (\%) & $72(53)$ & $32(63)$ & $40(47)$ & .15 \\
\hline CBV deficit in caudate nucleus or ACA territory (No.) (\%) & $54(39)$ & $28(55)$ & $26(30)$ & $.004^{\mathrm{b}}$ \\
\hline Permeability ratio (median) (IQR) ${ }^{c}$ & $1.36(1.13-1.88)$ & $1.66(1.24-2.60)$ & $1.30(1.09-1.54)$ & $.002^{\mathrm{b}}$ \\
\hline \multicolumn{5}{|l|}{ CTA } \\
\hline Clot burden score $\leq 6$ (No.) (\%) & $99(73)$ & $44(86)$ & $55(65)$ & $.006^{\mathrm{b}}$ \\
\hline Thrombus location ICA/Ml proximal (No.) (\%) & $63(48)$ & $33(67)$ & $30(36)$ & $.001^{\mathrm{b}}$ \\
\hline Poor collateral score (No.) (\%) & $62(46)$ & $34(68)$ & $28(33)$ & $.0001^{\mathrm{b}}$ \\
\hline \multicolumn{5}{|l|}{ Follow-up CTP and CTA } \\
\hline No recanalization ${ }^{c}$ & $26(33)$ & $6(32)$ & $20(33)$ & .89 \\
\hline No reperfusion ${ }^{c}$ & $45(62)$ & $16(76)$ & $29(56)$ & .10 \\
\hline
\end{tabular}

Note:-IQR indicates interquartile range.

${ }^{a} \chi^{2}$ was used to compare categoric variables, and a $t$ test or Mann-Whitney $U$ test, continuous variables.

${ }^{\mathrm{b}}$ All $P<.05$.

'The analysis of permeability ratio, recanalization, and reperfusion is a subanalysis on 101,79 , and 73 cases, respectively.

3.0 days (interquartile range, $2.0-4.0$ days) and was not statistically different between patients with and without prominent space-occupying edema. Permeability estimates were only available in 101 patients; and recanalization and reperfusion data, in 79 and 73 patients, respectively.

Patients who developed prominent space-occupying edema had a higher NIHSS score on admission. In addition, early CT signs of infarction (lower ASPECTS), larger CBV deficit (lower ASPECTS), decreased CBV in the caudate nucleus or ACA territory, higher permeability estimates, ICA/proximal M1 occlusions, higher clot burden, and worse collateral scores were more often found in patients with prominent space-occupying edema (all, $P<$.05). Time to admission scan, percentage of patients treated with IV-rtPA or intra-arterial treatment, recanalization, and reperfusion were not significantly different between patients with large infarcts and prominent space-occupying edema and those without prominent space-occupying edema (Table 1). The ORs of univariate regression are summarized in Table 2.

After adjustment for age and NIHSS score, the adjusted OR (Table 2) for prominent space-occupying edema remained significantly higher, with more early CT signs of infarction, larger CBV deficit size, higher permeability estimates, more proximal thrombus location, higher clot burden, and poor collateral scores.

\section{DISCUSSION}

The main finding of this study was that in patients with a large MCA infarct on follow-up, CT signs of infarction on admission NCCT, larger CBV deficits and higher permeability estimates on admission CTP, proximal thrombus location, a higher clot bur- den, and worse collateral scores on admission CTA are significantly associated with the development of prominent space-occupying edema. These findings suggest that patients who develop prominent space-occupying edema already have an extensive proximal clot and poor collaterals on admission.

Space-occupying edema develops as a combination of swelling of ischemic brain cells (cytotoxic edema) and leakage of fluid through the BBB (vasogenic edema). ${ }^{28}$ It is known that the balance between this edema formation and the brain regulatory systems (cerebrovascular autoregulation) that normally maintains cerebral perfusion pressure is impaired in patients with prominent space-occupying edema. ${ }^{29}$ This imbalance possibly occurs because of early involvement of a large ischemic area.

This is supported by the more extensive early CT signs of infarction and larger CBV deficits on admission in patients with prominent space-occupying edema, while the time to scanning was not significantly different from that in patients without prominent space-occupying edema. We suggest that the early development of a large ischemic area in patients with prominent space-occupying edema is a consequence of an extensive proximal clot in combination with poor leptomeningeal collateral status, thereby causing a larger ischemic deficit and increased permeability.

The large MCA infarcts on follow-up in patients without prominent space-occupying edema are presumably the result of a more gradually occurring process. The initial thrombus in these patients is located more distally, and this thrombus may extend more proximally with time. Therefore, areas that still maintained 


\section{OR $(95 \% \mathrm{Cl}) \quad$ aOR $(95 \% \mathrm{Cl})$}

\begin{tabular}{|c|c|c|}
\hline \multicolumn{3}{|l|}{ Clinical parameters } \\
\hline Age (per yr) & $0.99(0.96-1.01)$ & NA \\
\hline Female sex & $1.17(0.57-2.40)$ & $0.88(0.41-1.90)$ \\
\hline Prior stroke & $1.90(0.73-4.95)$ & $2.08(0.74-5.91)$ \\
\hline Atrial fibrillation & $1.79(0.63-5.11)$ & $2.74(0.86-8.70)$ \\
\hline NIHSS (per point) & $1.12(1.04-1.21)^{\mathrm{a}}$ & NA \\
\hline IV-rtPA & $0.65(0.31-1.36)$ & $0.56(0.25-1.22)$ \\
\hline Intra-arterial treatment & $1.04(0.45-2.42)$ & $1.03(0.42-2.49)$ \\
\hline \multicolumn{3}{|l|}{ Imaging parameters } \\
\hline Time to admission scan (per min) & $1.002(0.997-1.007)$ & $1.003(0.999-1.006)$ \\
\hline \multicolumn{3}{|l|}{ NCCT } \\
\hline Early CT signs of infarction, ASPECTS (0-10) & $1.32(1.14-1.53)^{\mathrm{a}}$ & $1.32(1.13-1.55)^{\mathrm{a}}$ \\
\hline \multicolumn{3}{|l|}{ CTP } \\
\hline CBV deficit, ASPECTS (0-10) & $1.30(1.12-1.52)^{a}$ & $1.26(1.07-1.49)^{\mathrm{a}}$ \\
\hline MTT deficit, ASPECTS (0-10) & $1.20(0.98-1.46)$ & $1.14(0.93-1.41)$ \\
\hline CBV deficit in lentiform nucleus & $1.90(0.93-3.85)$ & $1.53(0.72-3.22)$ \\
\hline CBV deficit in caudate nucleus or ACA territory & $2.81(1.37-5.76)^{a}$ & $2.01(0.93-4.32)$ \\
\hline Permeability ratio ${ }^{\mathrm{b}}$ & $2.08(1.21-3.60)^{\mathrm{a}}$ & $2.35(1.30-4.24)^{\mathrm{a}}$ \\
\hline \multicolumn{3}{|l|}{ CTA } \\
\hline Clot burden score $\leq 6$ & $3.43(1.38-8.55)^{\mathrm{a}}$ & $2.88(1.11-7.45)^{\mathrm{a}}$ \\
\hline Thrombus location & $3.64(1.73-7.69)^{\mathrm{a}}$ & $3.40(1.57-7.37)^{\mathrm{a}}$ \\
\hline ICA/M1 proximal versus $\mathrm{M} 1$ distal, $\mathrm{M} 2$, or $>\mathrm{M} 2$ & & \\
\hline Poor collateral score & $4.33(2.05-9.13)^{\mathrm{a}}$ & $3.93(1.78-8.69)^{a}$ \\
\hline \multicolumn{3}{|l|}{ Follow-up CTP and CTA } \\
\hline No recanalization ${ }^{\mathrm{b}}$ & $0.92(0.31-2.79)$ & $0.92(0.30-2.81)$ \\
\hline No reperfusion ${ }^{\mathrm{b}}$ & $2.54(0.81-7.96)$ & $2.18(0.67-7.07)$ \\
\hline
\end{tabular}

Note:-aOR indicates adjusted odds ratio (for age and NIHSS); NA, not applicable.

${ }^{a}$ All $P<.05$.

${ }^{\mathrm{b}}$ The analysis of permeability ratio, recanalization, and reperfusion is a subanalysis on 101,79 , and 73 cases respectively.

velop. ${ }^{3}$ Although our findings support the suggestion that collaterals are insufficiently present in patients who develop prominent space-occupying edema, we did not find a significant difference in the history of atrial fibrillation. There is still much controversy about the role of collaterals in both chronic and acute occlusive disease and whether cerebral collaterals can develop with time. Our study cannot provide answers for this discussion.

Jaramillo et $\mathrm{al}^{12}$ showed, in a postmortem analysis of 45 patients, that anterior cerebral artery territory infarcts were associated with prominent spaceoccupying edema. Moreover, another study reported that ACA involvement contributes to mortality as a mediator of collateral circulation. ${ }^{19}$ Our results did not show a significant relation between additional ACA vascular territory, with or without caudate nucleus involvement, and prominent space-occupying edema. A major difference between our study and the study of Jaramillo et al is that their assessment was performed postmortem after a median of

sufficient cerebral perfusion on admission could become infarcted on NCCT on day 3. There was no significant association between treatment with IV-rtPA on admission and recanalization or reperfusion status at day 3 (though recanalization and reperfusion data were only available in $55 \%-74 \%$ of patients). This finding also suggests that the early large extent of the MCA infarct and not recanalization or reperfusion is of importance for the development of prominent space-occupying edema. ${ }^{30}$ Moreover, thrombolytic treatment cannot influence the early cascade of events leading to prominent space-occupying edema.

Permeability estimates were a significant factor in univariate regression and after adjusting for age and admission NIHSS. This finding is in agreement with a retrospective study of 120 patients (with 12 patients treated with a hemicraniectomy for prominent space-occupying edema) that showed an association between increased infarct permeability surface area and prominent spaceoccupying edema occurrence. ${ }^{9}$ A relation between the duration of ischemia and the extent of damage to the BBB has also been shown previously. ${ }^{31,32}$ The time between symptom onset and the scan series was shorter in our data (100 minutes versus 310 minutes). This difference suggests that the BBB damage already occurred early in patients who developed prominent space-occupying edema.

The cause of prominent space-occupying edema in patients with large MCA infarction has not been clarified so far, to our knowledge. A study of 818 patients with 208 large MCA infarcts showed that atrial fibrillation was more frequent in these infarcts. The authors suggested that a cardiac embolus, in contrast to atherosclerotic thrombi from carotid stenosis, occludes a cerebral artery abruptly, leaving little time for collateral pathways to de-
18 days, while we assessed the admission CT scan obtained within 9 hours of symptom onset. ${ }^{12}$ The ACA can infarct at a later time point, secondary to ACA compression caused by subfalcine herniation. ${ }^{33}$ This scenario suggests that the ACA involvement in their study was a consequence, rather than a cause, of space-occupying edema formation.

Although age did not make a significant difference in the development of prominent space-occupying edema, generalized atrophy in older patients (as demonstrated in Fig 2A) could protect against the occurrence of substantial mass effect. However, we did not collect these data to investigate this variable.

Strengths of this study are the prospective collection of a large number of patients with prominent space-occupying edema and the combined use of clinical data with NCCT, CTA, and CTP data.

This study also has some limitations. First, our definition of prominent space-occupying edema was based on follow-up NCCT only. In other articles, clinical deterioration was quantified and also considered in the definition of prominent space-occupying edema or malignant MCA infarction. ${ }^{12,14,30}$ It is, however, unlikely that patients with prominent space-occupying edema or substantial hemorrhage were missed because additional CT scans were always obtained in case of clinical deterioration during the hospital stay.

Second, the exact time of recanalization was unclear because follow-up scans were obtained after $3 \pm 2$ days because we had to compromise between short- and long-term follow-up, to reduce potential radiation risks associated with multiple scans. This potential bias makes it necessary to interpret the results of our recanalization and reperfusion data with caution. 
Third, 9 patients were excluded because of poor-quality CTP at admission due to technical issues $(n=4)$ and patient movement $(n=5)$. The 3 -month mRS score between these 9 excluded patients and the 137 included patients was not significantly different, so it is unlikely that these exclusions caused any bias.

Fourth, patients with early spontaneous recanalization could potentially have influenced our results because CTP and CTA parameters may not always be accurate. However, in these patients, the ischemic changes on NCCT should still be indicative of the severity of the ischemia and thereby associated with prominent mass effect.

\section{CONCLUSIONS}

In patients with large MCA infarctions on follow-up, early CT signs of infarction on admission NCCT, larger CBV deficits, and higher permeability estimates on admission CTP and more proximal thrombus location, higher clot burden, and worse collateral scores on admission CTA were significantly associated with prominent space-occupying edema. These findings suggest that the prominent space-occupying edema in these patients develops due to a combination of extensive proximal occlusion and poor collaterals, which rapidly leads to a large area of ischemia with increased permeability.

\section{ACKNOWLEDGMENTS}

The DUST study investigators are the following: Academic Medical Center, Amsterdam, the Netherlands (Majoie CB, Roos YB); Catharina Hospital, Eindhoven, the Netherlands (Duijm LE, Keizer K); Erasmus Medical Center, Rotterdam, the Netherlands (van der Lugt A, Dippel DW); Gelre Hospitals, Apeldoorn, the Netherlands (Droogh-de Greve KE, Bienfait HP); Leiden University Medical Center, Leiden, the Netherlands (van Walderveen MA, Wermer MJ); Medical Center Haaglanden, The Hague, the Netherlands (Lycklama à Nijeholt GJ, Boiten J); Onze Lieve Vrouwe Gasthuis, Amsterdam, the Netherlands (Duyndam D, Kwa VI); Radboud University Nijmegen Medical Centre, Nijmegen, the Netherlands (Meijer FJ, van Dijk EJ); Rijnstate Hospital, Arnhem, the Netherlands (Kesselring FO, Hofmeijer J); St. Antonius Hospital, Nieuwegein, the Netherlands (Vos JA, Schonewille WJ); St. Elisabeth Hospital, Tilburg, the Netherlands (van Rooij WJ, de Kort PL); St. Franciscus Hospital, Rotterdam, the Netherlands (Pleiter CC, Bakker SL); VU Medical Center, Amsterdam, the Netherlands (Bot J, Visser MC); University Medical Center Utrecht, Utrecht, the Netherlands (Velthuis BK, van der Schaaf IC, Dankbaar JW, Mali WP, van Seeters T, Horsch AD, Niesten JM, Biessels GJ, Kappelle LJ, Luitse MJ, van der Graaf Y).

Disclosures: Birgitta K. Velthuis—RELATED: Grant: Dutch Heart Foundation (2008T034), * NutsOhra Foundation (0903-012)*; UNRELATED: Payment for Lectures (including service on Speakers Bureaus): regular presenter for Philips Healthcare.* Jan W. Dankbaar—RELATED: Grant: Dutch Heart Foundation 2012T061. Edwin BenninkRELATED: Grant: Netherlands Technology Foundation Stichting voor de Technische Wetenschappen (grant number 11632).* L.J. Kappelle-UNRELATED: Consultancy: Boehringer Ingelheim, Bayer HealthCare, Bristol-Meyers Squibb; Payment for Lectures (including service on Speakers Bureaus): Boehringer Ingelheim, Bayer HealthCare, Bristol-Meyers Squibb. *Money paid to the institution.

\section{REFERENCES}

1. Hacke W, Schwab S, Horn M, et al. 'Malignant' middle cerebral artery territory infarction: clinical course and prognostic signs. Arch Neurol 1996;53:309-15 CrossRef Medline

2. Berrouschot J, Sterker M, Bettin S, et al. Mortality of space-occupying ('malignant') middle cerebral artery infarction under conservative intensive care. Intensive Care Med 1998;24:620-23 CrossRef Medline

3. Heinsius T, Bogousslavsky J, Van Melle G. Large infarcts in the middle cerebral artery territory: etiology and outcome patterns. $\mathrm{Neu}$ rology 1998;50:341-50 CrossRef Medline

4. Vahedi K, Hofmeijer J, Juettler E, et al; DECIMAL, DESTINY, and HAMLET investigators. Early decompressive surgery in malignant infarction of the middle cerebral artery: a pooled analysis of three randomised controlled trials. Lancet Neurol 2007;6:215-22 CrossRef Medline

5. Hofmeijer J, Kappelle LJ, Algra A, et al; HAMLET investigators. Surgical decompression for space-occupying cerebral infarction (the Hemicraniectomy After Middle Cerebral Artery infarction with Life-threatening Edema Trial [HAMLET]): a multicentre, open, randomised trial. Lancet Neurol 2009;8:326-33 CrossRef Medline

6. Arch AE, Sheth KN. Malignant cerebral edema after large anterior circulation infarction: a review. Curr Treat Options Cardiovasc Med 2014;16:275 CrossRef Medline

7. Hofmeijer J, Algra A, Kappelle LJ, et al. Predictors of life-threatening brain edema in middle cerebral artery infarction. Cerebrovasc Dis 2008;25:176-84 CrossRef Medline

8. Rudolf J, Grond M, Stenzel C, et al. Incidence of space-occupying brain edema following systemic thrombolysis of acute supratentorial ischemia. Cerebrovasc Dis 1998;8:166-71 CrossRef Medline

9. Bektas H, Wu TC, Kasam M, et al. Increased blood-brain barrier permeability on perfusion CT might predict malignant middle cerebral artery infarction. Stroke 2010;41:2539-44 CrossRef Medline

10. Bennink E, Riordan AJ, Horsch $\mathrm{AD}$, et al. A fast nonlinear regression method for estimating permeability in CT perfusion imaging. J Cereb Blood Flow Metab 2013;33:1743-51 CrossRef Medline

11. Sykora M, Steiner T, Rocco A, et al. Baroreflex sensitivity to predict malignant middle cerebral artery infarction. Stroke 2012;43:714-19 CrossRef Medline

12. Jaramillo A, Góngora-Rivera F, Labreuche J, et al. Predictors for malignant middle cerebral artery infarctions: a postmortem analysis. Neurology 2006;66:815-20 CrossRef Medline

13. Wartenberg KE. Malignant middle cerebral artery infarction. Curr Opin Crit Care 2012;18:152-63 CrossRef Medline

14. Minnerup J, Wersching H, Ringelstein EB, et al. Prediction of malignant middle cerebral artery infarction using computed tomography-based intracranial volume reserve measurements. Stroke 2011; 42:3403-09 CrossRef Medline

15. van Seeters T, Biessels GJ, van der Schaaf IC, et al. Prediction of outcome in patients with suspected acute ischaemic stroke with CT perfusion and CT angiography: the Dutch Acute Stroke Trial (DUST) study protocol. BMC Neurol 2014;14:37 CrossRef Medline

16. Barber PA, Demchuk AM, Zhang J, et al. Validity and reliability of a quantitative computed tomography score in predicting outcome of hyperacute stroke before thrombolytic therapy: ASPECTS Study Group-Alberta Stroke Programme Early CT Score. Lancet 2000; 355:1670-74 CrossRef Medline

17. Hacke W, Kaste M, Fieschi C, et al. Intravenous thrombolysis with recombinant tissue plasminogen activator for acute hemispheric stroke: the European Cooperative Acute Stroke Study (ECASS). JAMA 1995;274:1017-25 CrossRef Medline

18. Dohmen C, Galldiks N, Bosche B, et al. The severity of ischemia determines and predicts malignant brain edema in patients with large middle cerebral artery infarction. Cerebrovasc Dis 2012;33: 1-87 CrossRef Medline

19. Walcott BP, Miller JC, Kwon CS, et al. Outcomes in severe middle cerebral artery ischemic stroke. Neurocrit Care 2014;21:20-26 CrossRef Medline 
20. van Seeters T, Biessels GJ, Niesten JM, et al; Dust Investigators. Reliability of visual assessment of non-contrast CT, CT angiography source images and CT perfusion in patients with suspected ischemic stroke. PLoS One 2013;8:e75615 CrossRef Medline

21. Kasner SE, Demchuk AM, Berrouschot J, et al. Predictors of fatal brain edema in massive hemispheric ischemic stroke. Stroke 2001; 32:2117-23 CrossRef Medline

22. Soares BP, Tong E, Hom J, et al. Reperfusion is a more accurate predictor of follow-up infarct volume than recanalization: a proof of concept using CT in acute ischemic stroke patients. Stroke 2010; 41:e34-40 CrossRef Medline

23. Puetz V, Dzialowski I, Hill MD, et al; Calgary CTA Study Group. Intracranial thrombus extent predicts clinical outcome, final infarct size and hemorrhagic transformation in ischemic stroke: the clot burden score. Int J Stroke 2008;3:230-36 CrossRef Medline

24. Tan IY, Demchuk AM, Hopyan J, et al. CT angiography clot burden score and collateral score: correlation with clinical and radiologic outcomes in acute middle cerebral artery infarct. AJNR Am J Neuroradiol 2009;30:525-31 CrossRef Medline

25. Tan JC, Dillon WP, Liu S, et al. Systematic comparison of perfusion-CT and CT-angiography in acute stroke patients. Ann Neurol 2007;61:533-43 CrossRef Medline

26. El-Mitwalli A, Saad M, Christou I, et al. Clinical and sonographic patterns of tandem internal carotid artery/middle cerebral artery occlusion in tissue plasminogen activator-treated patients. Stroke 2002;33:99-102 CrossRef Medline
27. Tomsick T, Broderick J, Carrozella J, et al; Interventional Management of Stroke II Investigators. Revascularization results in the Interventional Management of Stroke II trial. AJNR Am J Neuroradiol 2008;29:582-87 CrossRef Medline

28. Heo JH, Han SW, Lee SK. Free radicals as triggers of brain edema formation after stroke. Free Radic Biol Med 2005;39:51-70 CrossRef Medline

29. Dohmen C, Bosche B, Graf R, et al. Identification and clinical impact of impaired cerebrovascular autoregulation in patients with malignant middle cerebral artery infarction. Stroke 2007;38:56-61 CrossRef Medline

30. Thomalla G, Hartmann F, Juettler E, et al; Clinical Trial Net of the German Competence Network Stroke. Prediction of malignant middle cerebral artery infarction by magnetic resonance imaging within 6 hours of symptom onset: a prospective multicenter observational study. Ann Neurol 2010;68:435-45 CrossRef Medline

31. Ito U, Go KG, Walker JT Jr, et al. Experimental cerebral ischemia in Mongolian gerbils. III: behaviour of the blood-brain barrier. Acta Neuropathol 1976;34:1-6 CrossRef Medline

32. Todd NV, Picozzi P, Crockard A, et al. Duration of ischemia influences the development and resolution of ischemic brain edema. Stroke 1986;17:466-71 CrossRef Medline

33. Grossman RI, Yousem DM. Neuroradiology: The Requisites. 2nd ed. Philadelphia: Mosby, Elsevier; 2003:261-63 